\title{
Novel small molecule protein kinase CK2 inhibitors exert potent antitumor effects on T98G and SEGA cells in vitro
}

\author{
Emanuela Pucko, Robert P. Ostrowski, Ewa Matyja \\ Department of Experimental and Clinical Neuropathology, Mossakowski Medical Research Centre Polish Academy of Sciences, \\ Warsaw, Poland
}

\begin{abstract}
Tumours of astroglial origin, both malignant glioblastoma (GBM) and benign subependymal giant cell astrocytoma (SEGA), pose a serious medical problem. Casein kinase 2 (CK2), a member of the serine/threonine kinase family, has antiapoptotic properties and plays a vital role in glial tumour cell survival. It contributes to invasive cell growth and is often upregulated in malignant neoplastic cells; however, its role in benign tumours of astrocytic origin is less understood. In the present study we investigated the effects of small molecule CK2 inhibitors on proliferation and viability of glioma cells in vitro. The experiments were conducted on commercial T98G malignant glioma cell line and the SEGA cell line, derived from a paediatric case of tuberous sclerosis complex (TSC). Cell cultures were incubated with selected CK2 inhibitors: 4,5,6,7-tetrabromo-1H-benzimidazole (TBI), 2-dimethylamino-4,5,6,7-tetrabromo-1H-benzimidazole (DMAT) and 4,5,6,7-tetrabromo-1H-benzotriazole (TBB) at 0.1, 1, 10, 25, 50, 75 and $100 \mu \mathrm{M}$ concentrations for 24 and 48 hours. Cell proliferation was assessed using a cell counter and cell viability was evaluated by MTT assay. TBB at $75 \mu \mathrm{M}$ and $100 \mu \mathrm{M}$, and TBI starting from $25 \mu \mathrm{M}$, both reduced T98G cell proliferation after 24 hours, while DMAT was ineffective. All tested small molecule CK2 inhibitors appear to reduce T98G cell growth and viability after 48 hours, although TBI appeared to be the most effective and reduced cell growth in the 50-100 $\mu \mathrm{M}$ dose range. TBI also showed potential efficacy in reducing the number and viability of SEGA cells after 48 hours. Proliferation and viability of SEGA cells have proven resistant to TBB treatment. DMAT only reduced the viability of SEGA cells at 24 (at $100 \mu \mathrm{M})$ and 48 hours (10-100 $\mathrm{MM}$ ). Importantly, normal human astrocyte cells were found to be moderately resistant to TBB, while their viability was mildly reduced at higher doses of DMAT and TBI. In conclusion, CK2 appears to play a role not only in malignant glioma cells but it can also sustain the viability and proliferation of benign astrocytoma cells. The obtained antitumor effects of CK2 inhibitors significantly exceeded their mild or no effect on normal astrocytes in control, which supports the therapeutic potential of these compounds against gliomas.
\end{abstract}

Key words: Casein kinase inhibitors, CK2, antitumor activity, glioma cell lines, glioblastoma.

\section{Introduction}

Glial tumours are the largest group of primary neoplasms of the central nervous system (CNS) and most of them originate from astrocytes. The majori- ty of them are "diffuse" by definition of the current World Health Organization (WHO) classification of tumours of the central nervous system and correspond to grade II-IV of histological malignancy [27]. The so-called "other astroglial tumours" comprise

Communicating author:

Emanuela Barbara Pucko, PhD, Department of Experimental and Clinical Neuropathology, Mossakowski Medical Research Centre Polish Academy of Sciences, 5 Pawinskiego St., 02-106 Warsaw, Poland, e-mail: epucko@imdik.pan.pl 
a group of neoplasms well separated from the surrounding tissues, including subependymal giant cell astrocytoma (SEGA). Untreated SEGA tumours are associated with severe complications which can lead to patient death [1]. Thus, it is extremely important to find appropriate methods of treatment, as the surgery of brain tumours in children is associated with a substantial mortality and postoperative neurological deficits [23].

The latter holds true also for neoplasms with a higher degree of malignancy, including glioblastoma, which is the most malignant brain tumour, accounting for $70 \%$ of neoplasms of astrocytic origin in adults. The reason for the low efficacy of anti-cancer treatments may be blood-brain barrier, significant genotypic and phenotypic heterogeneity and the subpopulation of glioma stem-like cells (GSCs), which are at least partially responsible for high resistance to therapy [6]. Current therapeutic strategies, including surgery, radiotherapy, and chemotherapy with temozolomide, have increased the median survival to only 16-18 months, while the addition of lomustine, an alkylating drug, extends the patients survival time to 23.1 months. Unfortunately, only $3-5 \%$ of patients with diagnosed gliomas survive more than 3 years $[4,16,17]$. The problem of resistance of malignant glioma to the medical treatment is associated with abnormalities of the intracellular signalling pathways. A number of mutations have been detected in CNS tumour cells, including genes involved in apoptosis and kinase-coding genes that play an important role in vital cellular functions such as viability, differentiation and proliferation. It is believed that tumour progression is related to various intracellular signal transduction pathways that involve the activation of protein kinases [29], including casein kinase (CK2).
The aim of the study was to assess the antitumor properties of small molecule protein kinase CK2 inhibitors: 2-dimethylamino-4,5,6,7-tetrabromo-1Hbenzimidazole (DMAT), 4,5,6,7-tetrabromo-1H-benzimidazole (TBI) and 4,5,6,7-tetrabromo-1H-benzotriazole (TBB) on the growth and cell viability of the human low and high grade glioma cell lines.

\section{Material and methods \\ Tested chemicals}

To study antitumor effects we used the selected CK2 inhibitors (Fig. 1): 4,5,6,7-tetrabromo-1H-benzimidazole (TBI), 2-dimethylamino-4,5,6,7-tetrabromo1H-benzimidazole (DMAT) and 4,5,6,7-tetrabromo$1 \mathrm{H}$-benzotriazole (TBB). The TBB and TBI were obtained by excessive bromination of $1 \mathrm{H}$-benzimidazole or $1 \mathrm{H}$-benzotriazole as described $[2,38]$. DMAT was synthesized according to previously described procedures [32].

All experiments were performed on cell lines established from human glioblastoma (T98G) cells, SEGA cells and astrocyte cells. The T98G cell line was obtained from the American Type Culture Collection (Manassas, VA, USA). Glioblastoma cells were grown in Eagle's minimum Essential medium (SigmaAldrich Chemie $\mathrm{GmbH}$, Munich, Germany), supplemented with $10 \%$ foetal bovine serum (Gibco, Invitrogen, Grand Island, NY, USA), 1\% penicillin/ streptomycin solution (Gibco Invitrogen), and 1\% non-essential amino acids (Sigma-Aldrich Chemie $\mathrm{GmbH}$ ). Cultures were maintained at $37^{\circ} \mathrm{C}$, in a humidified atmosphere, with $95 \%$ air $/ 5 \% \mathrm{CO}_{2}$. The cell line derived from SEGA was kindly provided by Professor K. Kotulska from the Department of Paediatric Neurology, The Children's Memorial Heath Institute, Warsaw, Poland. The SEGA specimen was originally obtained from a patient with tuberous sclerosis complex (TSC), diagnosed clinically accord-<smiles>CN(C)c1nc2c(Br)c(Br)c(Br)c(Br)c2[nH]1</smiles>

DMAT

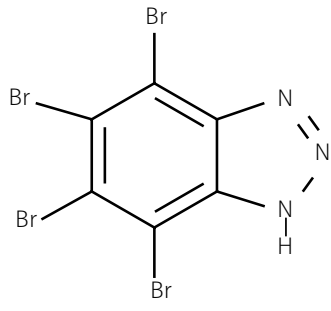

TBB<smiles>Brc1c(Br)c(Br)c2[nH]cnc2c1Br</smiles>

TBI

Fig. 1. Chemical structure of CK2 inhibitors: 2-dimethylamino-4,5,6,7-tetrabromo-1H-benzimidazole (DMAT), 4,5,6,7-tetrabromobenzotriazole (TBB), 4,5,6,7-tetrabromo-1H-benzimidazole (TBI). 
ing to the Roach criteria (the study was approved by the Committee of Bioethics of the Children's Memorial Health Institute, with written informed consent of the patient to participate in the study). SEGA-derived cell lines were grown in Dulbecco's modified Eagle's medium (Gibco, Invitrogen), supplemented with $10 \%$ foetal bovine serum (Gibco, Invitrogen) and a $1 \%$ solution of penicillin/streptomycin (Gibco, Invitrogen). Cultures were maintained at $37^{\circ} \mathrm{C}$, in a humidified atmosphere, with $95 \%$ air $/ 5 \% \mathrm{CO}_{2}$. Human astrocytes, originally obtained from ScienCell Research Laboratories (Carlsbad, CA, USA) and were grown in AM Astrocyte Medium (ScienCell), supplemented with $10 \%$ foetal bovine serum (Gibco, Invitrogen) and 1\% solution of penicillin/streptomycin (Gibco, Invitrogen) separately in dimethyl sulfoxide (DMSO; Sigma-Aldrich Chemie $\mathrm{GmbH}$ ) and added to the culture medium. T98G cells, SEGA cells and human astrocytes were seeded in 5 - or $10-\mathrm{cm}$ culture plates (Nunc ${ }^{\mathrm{TM}}$, Thermo Scientific ${ }^{\mathrm{TM}}$; Thermo Fisher Scientific, Waltham, MA, USA) and grown in the medium without (control) or with TBI, TBB, DMAT.

The final concentrations of tested compounds in the complete growth medium ranged from $0.1 \mu \mathrm{M}$ to $100 \mu \mathrm{M}$. Control cell cultures were treated with an equal volume of solvent (DMSO). The exact amount of DMSO (Sigma-Aldrich Chemie $\mathrm{GmbH}$ ) added to the control cells was $0.1 \%(\mathrm{v} / \mathrm{v})$ during cell treatment. The culture medium was replaced daily. The effects of the tested compounds were observed with a Nikon inverted microscope (Nikon, Tokyo, Japan).

Three independent cultures for each group were washed with phosphate-buffered saline (PBS; SigmaAldrich Chemie $\mathrm{GmbH}$ ) and trypsinized; the collected cells were centrifuged $\left(200 \times g\right.$ at $4^{\circ} \mathrm{C}$ for $5 \mathrm{~min}$ ). Pellets were resuspended in PBS, and the number of cells per millilitre was determined with a cell counter (Multisizer3, Beckman Coulter, Indianapolis, IN, USA). Each experimental group comprised three independent cultures, and each culture was tested in triplicate.

\section{Metabolic analysis of cell viability}

Cell viability was determined with a 3-(4,5-dimethylthiazol-2-yl)-2,5-diphenyl tetrazolium bromide (MTT; Sigma-Aldrich, Munich, Germany) colorimetric assay. Briefly, cells were cultured in 96-well plates (Nunc ${ }^{\mathrm{TM}}$, ThermoScientific ${ }^{\mathrm{TM}}$ ) with $0.1 \mu \mathrm{M}, 1 \mu \mathrm{M}, 10 \mu \mathrm{M}, 25 \mu \mathrm{M}$, $50 \mu \mathrm{M}, 75 \mu \mathrm{M}, 100 \mu \mathrm{M}$ of tested compounds or DMSO (Sigma-Aldrich Chemie $\mathrm{GmbH}$ ) in the medium. After
24 and 48 hours, cells were incubated in the culture medium supplemented with MTT at a final concentration of $0.5 \mathrm{mg} / \mathrm{ml}$. In actively metabolizing cells, MTT is converted to formazan, detected as dark blue crystals. Next, the medium was removed, the formazan crystals were dissolved in $200 \mu \mathrm{LMSO}$ and the plate was placed on a shaking table for $15 \mathrm{~min}$. Absorbance at $570 \mathrm{~nm}$ was measured with a spectrophotometer (Epoch microplate reader; BioTek, Winooski, VT, USA). All measurements were carried out in triplicates.

\section{Statistical analysis}

All experiments were repeated at least two times. Results were analysed with one-way analysis of variance, followed by Tukey's test. Results are expressed as the mean \pm standard deviation.

\section{Results \\ Effect of CK2 inhibitors on T98G malignant glioma cell proliferation}

TBB after 24 hours of incubation showed a statistically significant inhibition of cell growth at concentrations of $75 \mu \mathrm{M}$ and $100 \mu \mathrm{M}$. During this observation period, T98G glioblastoma cells were resistant to DMAT treatment in the concentration range of 10 to $100 \mu \mathrm{M}$. After 24 hours of exposure, TBI occurred to be most effective and reduced the number of glioma cells already at a concentration of $25 \mu \mathrm{M}$ and higher (Fig. 2A). After $48 \mathrm{~h}$ of treatment, human T98G glioma cells treated with TBI, DMAT, TBB showed a significant, dose-dependent reduction in the total number of neoplastic cells compared to control cultures (Fig. 2B).

Morphological evaluation of T98G malignant glioma cell line treated with TBI showed that application of this CK2 inhibitor at concentrations of 10, 25, 50, 75 and $100 \mu \mathrm{M}$ resulted in a decrease in the cell number (Fig. 3B, C, D, E, F) compared to untreated cultures (Fig. 3A). TBI appeared to be more effective after 48 hours, even when applied at a concentration of $50 \mu \mathrm{M}$ whereas concentrations of $75 \mu \mathrm{M}$ and $100 \mu \mathrm{M}$ resulted in advanced reduction in viable neoplastic cells (Fig. 3D-F).

\section{Effect of CK2 inhibitors on viability of T98G malignant glioma cells}

We performed an MTT metabolism assay and found that CK2 inhibitors reduced the viability of T98G glioma cells in a dose dependent manner (Fig. 4A, B). After treatment with TBB, DMAT and 

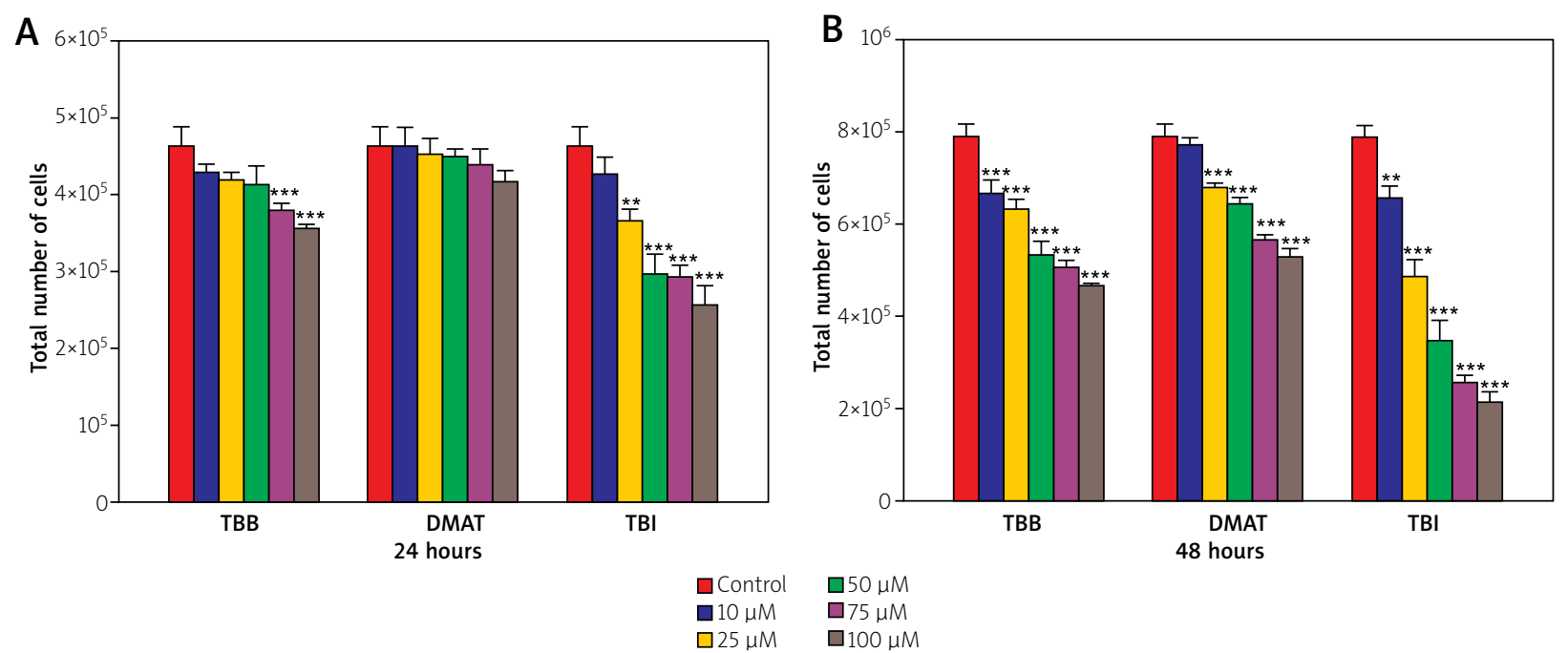

Fig. 2. Effect of CK2 inhibitors on the proliferation of T98G malignant glioma cells after (A) 24 hours (B) 48 hours. Data are the mean \pm SD of 9 replicates. Significantly different from the control at ${ }^{* *} p<0.01$, and ${ }^{* * *} p<0.001$

TBI, a significant decrease in T98G cell viability after 24 hours was observed (Fig. 4A). After 48 hours incubation with TBB and DMAT, the cell viability decreased by an average of $20 \%$ at $50 \mu \mathrm{M}$. Among the tested compounds, TBI was found to be the most effective and at a concentration of 50-100 $\mu \mathrm{M}$ caused a reduction in the number of cells by about $50-60 \%$ within 48 hours (Fig. 4B).

\section{Effect of CK2 inhibitors on SEGA cell proliferation}

SEGA cells treated with TBB or DMAT at a concentration of 10-100 $\mu \mathrm{M}$ did not show statistically significant changes in the number of cells on subsequent days of incubation compared to the control group. SEGA cells treated with TBI showed a significant reduc-
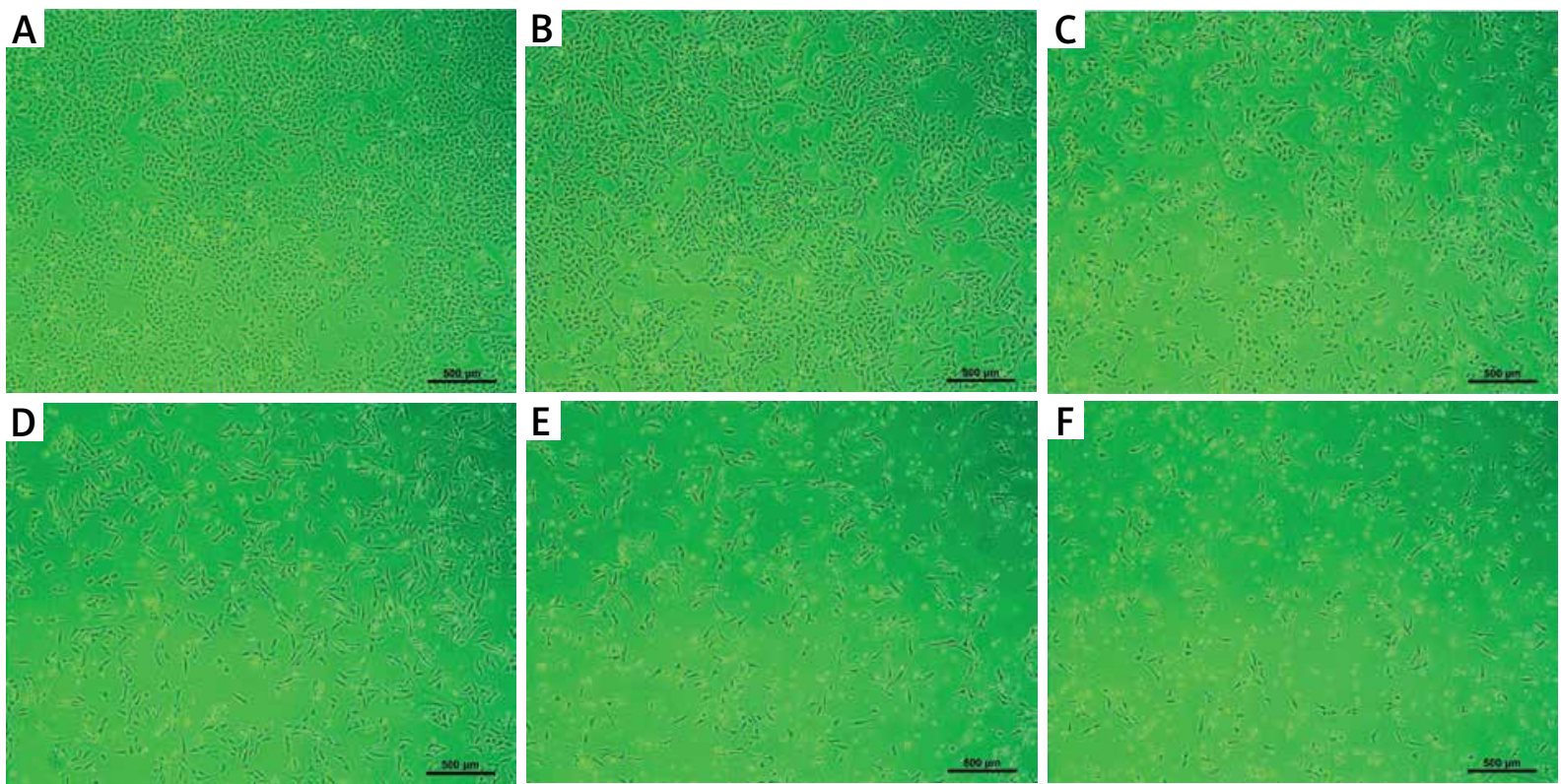

Fig. 3. Morphological evaluation of T98G malignant glioma cell line treated with TBI after 48 hours. 
A

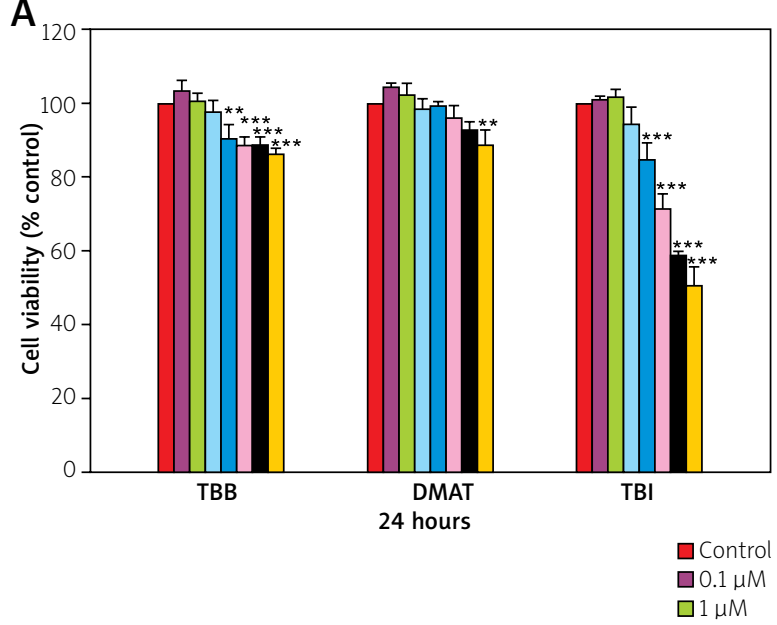

B

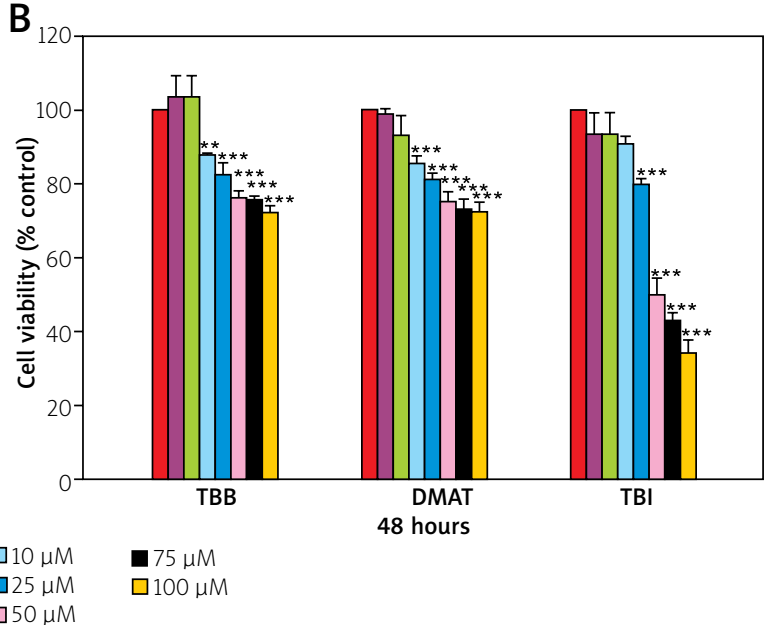

Fig. 4. Effect of CK2 inhibitors on the viability of T98G malignant glioma cells after (A) 24 hours and (B) 48 hours. Data are the mean \pm SD of 9 replicates. Significantly different from the control at ${ }^{* *} p<0.01,{ }^{* * *} p<0.001$.

tion in cell numbers after 24 hours of incubation with the tested compound at a concentration of 75-100 $\mu \mathrm{M}$ (Fig. 5A) and even at a concentration of $25 \mu \mathrm{M}$ after 48 hours, when compared to untreated cultures (Fig. 5B).

\section{Effect of CK2 inhibitors on SEGA cell viability}

After $24 \mathrm{~h}$, SEGA cells were resistant to TBB treatment (Fig. 6A). DMAT and TBI inhibited the viability of cultured SEGA cells after 24 and 48 hours of exposure (Fig. 6A, B). DMAT at concentrations of 0.1-75 $\mu \mathrm{M}$ did not affect cell viability after 24 hours, and only at the highest concentration of $100 \mu \mathrm{M}$, a decrease in cell via- bility was observed by more than $10 \%$ compared to the control group. After 48 hours, this compound at concentrations of 10-100 $\mu \mathrm{M}$ caused a statistically significant reduction in cell viability by more than $20 \%$. Among the tested compounds, TBI was found to be the most effective and at concentrations of 25 and $100 \mu \mathrm{M}$ induced a decrease in cell viability by about $50-82 \%$ of cells within $48 \mathrm{~h}$ of treatment (Fig. 6B).

\section{Effect of CK2 inhibitors on viability normal human astrocyte cells}

Normal human astrocyte cells were moderately resistant to TBB treatment at concentrations of
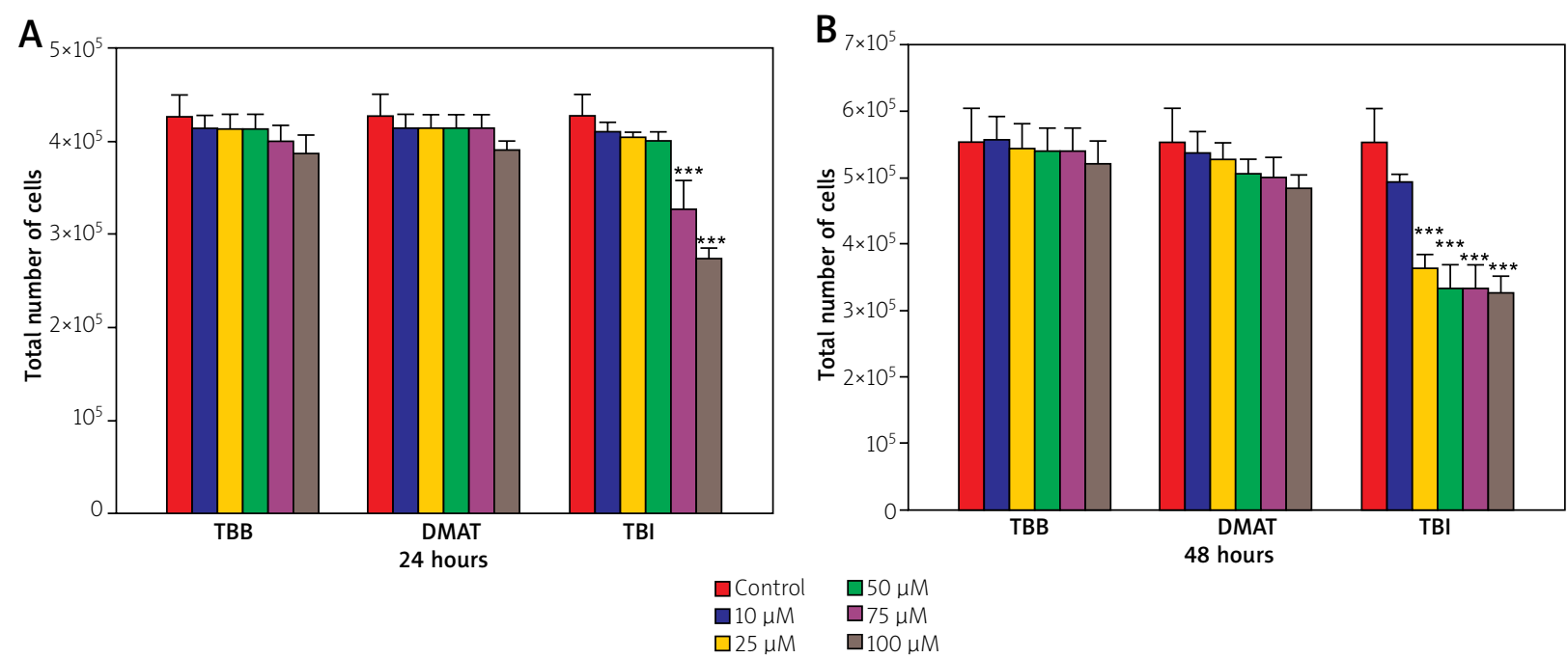

Fig. 5. Effect of CK2 inhibitors on the proliferation of SEGA cells after (A) 24 hours and (B) 48 hours. Data are the mean \pm SD of 9 replicates. Significantly different from the control at ${ }^{\star \star \star} p<0.001$. 

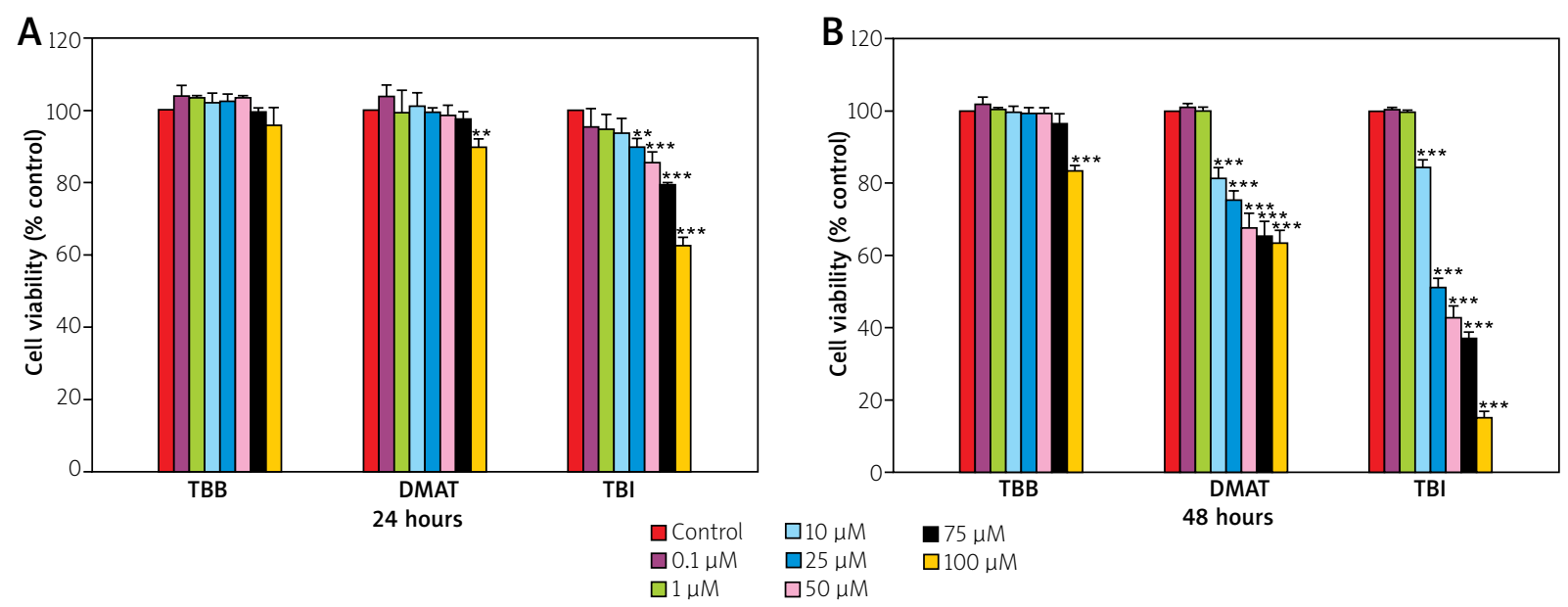

Fig. 6. Effect of CK2 inhibitors on the viability of T98G malignant glioma cells after (A) 24 hours and (B) 48 hours. Data are the mean \pm SD of 9 replicates. Significantly different from the control at ${ }^{* *} p<0.01$, ${ }^{* * *} p<0.001$.
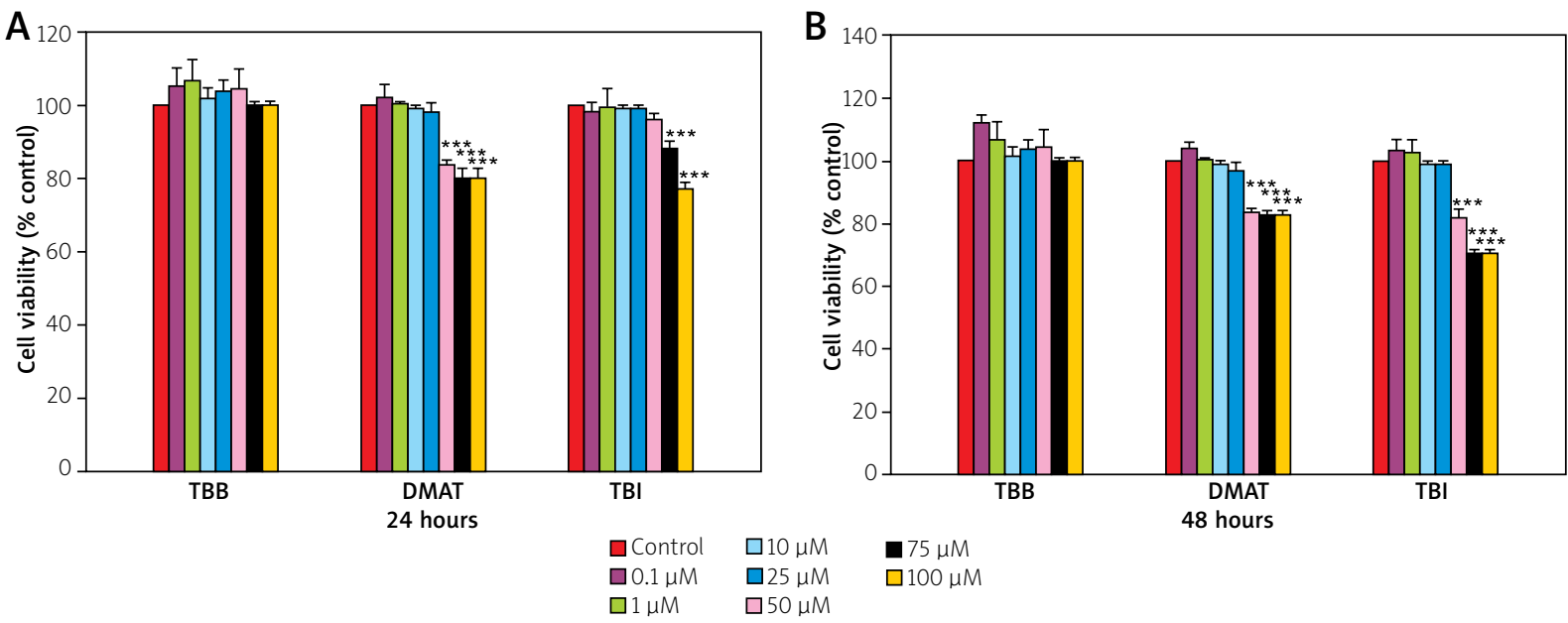

Fig. 7. Effect of CK2 inhibitors on the viability of astrocytes after (A) 24 hours and (B) 48 hours. Data are the mean \pm SD of 9 replicates. Significantly different from the control at ${ }^{* * *} p<0.001$.

$0.1 \mu \mathrm{M}$ to $100 \mu \mathrm{M}$ after 24 and 48 hours. DMAT at concentrations of $0.1 \mu \mathrm{M}, 1 \mu \mathrm{M}, 10 \mu \mathrm{M}$ and $25 \mu \mathrm{M}$ did not affect the viability of normal human astrocyte cells after 24 and 48 hours of incubation. Only at a concentration of $50 \mu \mathrm{M}$ and $100 \mu \mathrm{M}$, DMAT caused a statistically significant, more than $15 \%$ reduction in viability of human astrocyte after 24 and 48 hours, compared to the control group (Fig. 7A, B). TBI at a concentration of $0.1 \mu \mathrm{M}, 1 \mu \mathrm{M}, 10 \mu \mathrm{M}$ and $25 \mu \mathrm{M}$ did not affect the viability of human astrocytes cells after 24 and 48 hours of incubation. Only at a concentration of $75 \mu \mathrm{M}$ and $100 \mu \mathrm{M}$ after 24 hours of incubation with $\mathrm{TB}$ I there was a decrease in cell viability (Fig. 7A), whereas after 48 hours a decrease in viability was observed at $50 \mu \mathrm{M}, 75 \mu \mathrm{M}$ and $100 \mu \mathrm{M}$ of the tested compounds (Fig. 7B).

\section{Discussion}

The current studies show that CK2 inhibitors affect the proliferation and viability of cultured cells of both, human low-grade SEGA and high-grade glioblastoma. For both investigated tumours, despite differences in malignancy and clinical prognosis, there is no effective therapy. 
SEGA tumours are diagnosed in up to $20 \%$ of patients with tuberous sclerosis complex (TSC) $[15,25,37]$, caused by a mutation of the TSC 1 or the TSC2 genes [11]. Theories regarding the mechanism of creating SEGA nodules are still a matter of debate. It is rather unlikely that a mutation in the TSC1 or TSC2 gene alone would be responsible for their formation, especially since patients with SEGA without clinical symptoms associated with TSC have been reported [3]. Other studies indicate that posttranslational inactivation of the TSC1/TSC2 complex is formed by activating the AKT kinase, which can directly phosphorylate the tuberine, and as a result, deactivates TSC2. This mechanism is probably responsible for the activation of S6K by AKT [24]. Other published studies have shown that many genes including ANXA1, GPNMB, LTF, RND3, NPTX1 may be potentially involved in the development of SEGA tumours [36]. It has been found that the mammalian target of rapamycin (mTOR) is associated with the development of the disease and may be expected to play a major role in tumour progression [18] mTOR activation may be indicated by the increased Akt phosphorylation, high levels of phospho-S6K, phospho-S6 and phospho-STAT3 in the neoplastic astroglial cells. Recent clinical studies have shown that mTOR inhibitors may cause regression of SEGA associated with TSC and thus may become an alternative option to surgical treatment for patients not qualified for surgery [19]. However, application of mTOR inhibitors is related with adverse side effects and tumour regrows a few months after withdrawal of the inhibitor [30]. Since both surgical methods and targeted therapies for the mTOR pathway do not effectively reduce the SEGA recurrence, it is advisable to seek an alternative therapeutic strategy.

Also, in the cases of malignant glioma, there is no effective therapy to offer. Only 3-5\% of patients with diagnosed glioma survive for over 3 years and neurosurgery, radiotherapy and chemotherapy can only slightly increase the median of survival $[4,16,17]$. The prognosis for patients with GBM depends on the status of the IDH gene. Therefore, GBM is currently defined molecularly by mutations of genes coding isocitrate dehydrogenase 1 or 2 (IDH1/2) [12,21]. Primary, IDH wild-type GBM appears de novo and is associated with worse prognosis than IDH-mutant GBM developing from malignant transformation of the lower grade astrocytomas [27]. Nevertheless, regardless of molecular changes, GBM is associated with a very unfavourable prognosis and requires the search for new therapeutic approaches.

The results of the currently conducted studies are consistent with the belief that the progression of gliomas is associated with the activation of intracellular signalling mechanisms, including casein kinase II (CK2) pathways. CK2 is a hetero tetrameric and constitutively active serine-threonine kinase, composed of two catalytic ( $\alpha$ and/or $\alpha$ ) and two $\beta$ regulatory subunits. The role of CK2 in many pathologies is well known $[9,10]$. In particular, it is implicated in cardiovascular pathology, cerebral hypoxia, and neurodegeneration, including Alzheimer's disease [8]. CK2 also contributes to the development of tumour, neoplastic cell proliferation and suppression of apoptosis, and it is overexpressed in various types of cancers, including human glioblastoma [7,13,14,33]. Studies have shown that an abnormally elevated CK2 level is required for tumour progression due to its role in the regulation of almost all the processes essential for cancer development, including suppression of apoptosis. A large number of CK2 inhibitors are available, most of which belong to the class I of kinase inhibitors, i.e., compounds capable of directly targeting to an ATP-binding site. Benzimidazoles, coumarins and pyrazolotriazines are the most numerous families of CK2 inhibitors [10]. The inhibition of protein kinases, and in particular CK2 kinase, as specific molecular targets in anti-cancer therapy, has become one of the most promising therapeutic approaches to retard the growth and proliferation of various tumours. Protein kinase inhibitors have demonstrated significant anti-tumour activity [26].

One of the presently tested CK2 inhibitors, 4,5,6,7-tetrabromo- $1 \mathrm{H}$-benzotriazole (TBB), was created based on the structure of a known CK2 inhibitor, 5,6-dichlorobenzimidazole ribofuranoside [13]. TBB has been demonstrated as a quite selective and effective ATP site-directed inhibitor of protein kinase II with a low Ki value $(\mathrm{Ki}=0.4 \mu \mathrm{M})$. It fills the hydrophobic pocket that is present in all protein kinases but whose size in CK2 is perfectly fitting to the inhibitor molecule. Previous investigations have shown that in parallel to CK2 inhibition, TBB induces time- and dose-dependent cell death through apoptosis, suggesting that CK2 could actually counteract the programmed cell death [2,5,34]. Other studies showed that TBB led to a decrease in PTEN and Akt phosphorylation and was associated with the induction of apoptosis in human stromal cells in chronic lym- 
phocytic leukemia (CLL) [35]. Our research has documented that TBB at $0.1 \mu \mathrm{M}$ and $10 \mu \mathrm{M}$ concentration after 24 hours of incubation did not significantly reduce T98G cell viability. However, a significant reduction in cell viability was noted at higher concentrations, especially at $50 \mu \mathrm{M}, 75 \mu \mathrm{M}$ and $100 \mu \mathrm{M}$. Also SEGA cells and human astrocytes treated with TBB at various concentrations and incubation times, did not show reduction in cell proliferation and survival, with the exception of decreased SEGA viability at a concentration of $100 \mu \mathrm{M}$ after 48 hours. A slight cytotoxic effect of TBB was also obtained in other studies which showed that after 24-hour incubation with TBB at concentrations of $25 \mu \mathrm{M}$ and $50 \mu \mathrm{M}$, the viability of the T98G cell decreased by about $10 \%$, while the decrease in viability of LN229 astrocytoma cells was $15 \%$ [20]. On the other hand, C6 show rat glioma cells are not susceptible to TBB [20]. TBB showed selectivity for CK2 in the panel of 30 kinases; however, there were also other kinases to some extent sensitive to the inhibitor, including DYRK1a kinase. To improve the selectivity of CK2 inhibitors using the TBB backbone as a scaffold, two next generation derivatives, 2-dimethylamino4,5,6,7-tetrabromo- $1 \mathrm{H}$-benzimidazole (DMAT) and 4,5,6,7-tetrabromo-1H-benzimidazole (TBI or TBBz) were developed [13].

The second CK2 inhibitor tested in this work is 2-dimethylamino-4,5,6,7-tetrabromo-1 H-benzimidazole (DMAT) which exceeds TBB with several aspects. DMAT is characterized by a high affinity and selectivity towards $\mathrm{CK} 2$ and has the lowest Ki kinetic value among CK2 inhibitors $(\mathrm{Ki}=0.040 \mu \mathrm{M})$. DMAT does not inhibit CK1 kinase at concentrations up to $200 \mu \mathrm{M}$, easily penetrates into cells, and is several times more effective in vitro than TBB, both in terms of endogenous CK2 inhibition and apoptosis induction [31].

DMAT showed no significant effect on T98G cell proliferation over the concentration range of $10 \mu \mathrm{M}$ to $100 \mu \mathrm{M}$ after 24 hours of incubation. However, when the incubation time was extended to 48 hours, a statistically significant decrease in cell growth was achieved at DMAT concentrations higher than $10 \mu \mathrm{M}$. Moreover, DMAT reduced the viability of T98G cells after 24 and 48 hours incubation. Studies of other authors on LN229 glioma cells line, showed a decrease in cell viability by approximately $21 \%$ in the range of 10-50 $\mu \mathrm{M}$ after 24 hours of incubation [20]. 24-hour exposure of SEGA cells to DMAT at a concentration of $100 \mu \mathrm{M}$ DMAT caused a decrease in the viability of SEGA cells by more than $15 \%$. Extension of the incubation time to 48 hours resulted in a further reduction in cell viability. DMAT also reduced viability of astrocytes at concentrations of 50-100 $\mu \mathrm{M}$ after 24 and 48 hours. Other reports also indicate a positive effect of DMAT on various tumour cell lines. DMAT at a concentration of $10 \mu \mathrm{M}$ caused apoptosis in $20 \%$ of human acute myeloid leukemia (KG-1) cells after 24 and 48 hours of incubation [22]. DMAT, applied in combination with the pentabromobenzylisothiouronium bromides had a synergistic pro-apoptotic effect; the most potent synergistic effect was especially induced by combination with ZKK-13 after 48 hours of incubation [22]. On the other hand, the viability and proliferation of HeLa cells decreased by about $20 \%$ after 24 and 48 hours of incubation with $10 \mu \mathrm{M}$ DMAT [28]. A significant inhibitory effect on the viability of human adrenocortical cancer cell line (H295R) has been documented after 72 hours' incubation with DMAT at concentrations from $10^{-4}$ to $10^{-10} \mathrm{M}$, whereas a strong inhibitory effect on proliferation was obtained after 72 hours of incubation only at concentrations of $10^{-4}$ and $10^{-5} \mathrm{M}$ [26]. In addition, studies have shown that DMAT clearly activates caspases 3, 7, 8 in the T98G line, whereas in the cells of rat glioma C6, DMAT at the concentration of $50 \mu \mathrm{M}$ activates caspases 3 and 7 and causes PARP protein breakdown after 30-hour incubation, which confirms the induction of cell death via apoptosis [20]. The highest antiproliferative activity among the tested CK2 inhibitors was demonstrated by TBI. In T98G cells after incubation with TBI at concentrations of 25-100 $\mu \mathrm{M}$, statistically significant changes in cell viability were observed after 24 and 48 hours. The cytotoxic effect of TBI was also documented in other studies. After 24-hour incubation, TBI showed a reduction in cell viability when compared to the control also in rat glioma C6 cells [20].

In this present study, the effect of TBI on the growth and viability of SEGA cells showed a 10-19\% decrease in cell viability after 24 hours of incubation in the range of 25-75 $\mu \mathrm{M}$. At the incubation time of 48 hours and TBI concentration range of $50-100 \mu \mathrm{M}$, the viability was below $55 \%$. This compound showed a higher cytotoxic activity towards SEGA cells after 48 hours than towards T98G cells.

Interestingly, in the experiments with human astrocytes, it was found that TBI had no effect on 
astrocytes up to $50 \mu \mathrm{M}$ concentration after 24 hours of incubation, however after 48 hours of incubation at the concentration of $50 \mu \mathrm{M}$, the astrocyte viability decreased by about $19 \%$, whereas at the concentration of 75-100 $\mu \mathrm{M}$, the viability decreased by more than $35 \%$. Similar results were obtained in other studies on non-transformed astrocytes, in which no effect of 1-50 $\mu \mathrm{M}$ TBI on cell viability was documented after 24 hours of incubation, while there was a $20 \%$ decrease in their viability at $50 \mu \mathrm{M} \mathrm{TBI}$ after 48 hours [20].

\section{Conclusions}

In conclusion, our studies revealed that structurally related protein kinase CK2 inhibitors have unique biological properties in glioma cells. Some of these compounds administered at medium doses, showed a distinctively robust antitumor effect, having no impact on normal astrocytes, what speaks for the therapeutic potential of these CK2 inhibitors against glioma cells.

\section{Acknowledgements}

We wish to thank Professor Zygmunt Kazimierczuk for the opportunity to use CK2 inhibitors synthesized by himself. We thank Maria Zielińska for her technical assistance in Tissue Culture Laboratory.

\section{Source of funding}

The research was partly supported by the Foundation for the Development of Diagnostic and Therapy in Warsaw.

\section{Disclosure}

The authors report no conflict of interest.

\section{References}

1. Amin S, Lux A, Calder N, Laugharne M, Osborne J, O'Callaghan F. Causes of mortality in individuals with tuberous sclerosis complex. Dev Med Child Neurol 2017; 59: 612-617.

2. Andrzejewska M, Pagano MA, Meggio F, Brunati AM, Kazimierczuk Z. Polyhalogeno benzimidazoles: synthesis and their inhibitory activity against casein kinases. Bioorg Med Chem 2003; 11: 3997-4002.

3. Appalla D, Depalma A, Calderwood S. Mammalian target of rapamycin inhibitor induced complete remission of a recurrent subependymal giant cell astrocytoma in a patient without features of tuberous sclerosis complex. Pediatr Blood Cancer 2016; 63: 1276-1278.
4. Bleeker FE, Molenaar RJ, Leenstra S. Recent advances in the molecular understanding of glioblastoma. J Neurooncol 2012; 108: 11-27.

5. Borowiecki P, Wawro AM, Winska P, Wielechowska M, Bretner M. Synthesis of novel chiral TBBt derivatives with hydroxyl moiety. Studies on inhibition of human protein kinase CK2alpha and cytotoxicity properties. Eur J Med Chem 2014; 84: 364-374.

6. Bradshaw A, Wickremsekera A, Tan ST, Peng LF, Davis PF, Itinteang T. Cancer Stem Cell Hierarchy in Glioblastoma Multiforme. Front Surg 2016; 3.

7. Castello J, Ragnauth A, Friedman E, Rebholz H. CK2 - an emerging target for neurological and psychiatric disorders. Pharmaceuticals 2017; 10: E7.

8. Cozza G. The Development of CK2 inhibitors: from traditional pharmacology to in silico rational drug design. Pharmaceuticals 2017; 10: E26.

9. Cozza G, Pinna LA. Casein kinases as potential therapeutic targets. Expert Opin Ther Targets 2016; 20: 319-340.

10. 10. Cozza G, Pinna LA, Moro S. Kinase CK2 inhibition: an update. Curr Med Chem 2013; 20: 671-693.

11. De Waele L, Lagae L, Mekahli D. Tuberous sclerosis complex: the past and the future. Pediatr Nephrol 2015; 30: 1771-1780.

12. Diamandis P, Aldape KD. Insights from molecular profiling of adult glioma. J Clin Oncol 2017; 35: 2386-2393.

13. Duncan JS, Gyenis L, Lenehan J, Bretner M, Graves LM, Haystead TA, Litchfield DW. An unbiased evaluation of CK2 inhibitors by chemoproteomics: characterization of inhibitor effects on CK2 and identification of novel inhibitor targets. Mol Cell Proteomics 2008; 7: 1077-1088.

14. Ferrer-Font L, Villamanan L, Arias-Ramos N, Vilardell J, Plana M, Ruzzene M, Pinna LA, Itarte E, Arús C, Candiota AP. Targeting protein kinase CK2: evaluating CX-4945 potential for GL261 glioblastoma therapy in immunocompetent mice. Pharmaceuticals 2017; 10: E24.

15. Fogarasi A, De Waele L, Bartalini G, Jozwiak S, Laforgia N, Verhelst H, Petrak B, Pedespan JM, Witt O, Castellana R, Crippa S, Gislimberti G, Gyorsok Z. Effects: an expanded access program of everolimus for patients with subependymal giant cell astrocytoma associated with tuberous sclerosis complex. BMC Neurol 2016; 16: 126.

16. Glas M, Happold C, Rieger J, Wiewrodt D, Bahr O, Steinbach JP, Wick W, Kortmann RD, Reifenberger G, Weller M, Herrlinger U. Long-term survival of patients with glioblastoma treated with radiotherapy and lomustine plus temozolomide. J Clin Oncol 2009; 27: 1257-1261

17. Jakubowicz-Gil J, Langner E, Badziul D, Wertel I, Rzeski W. Apoptosis induction in human glioblastoma multiforme T98G cells upon temozolomide and quercetin treatment. Tumour Biol 2013; 34: 2367-2378.

18. Jozwiak J, Jozwiak S, Wlodarski P. Possible mechanisms of disease development in tuberous sclerosis. Lancet Oncol 2008; 9 : 73-79.

19. Jóźwiak S, Nabbout R, Curatolo P; participants of the TSC Consensus Meeting for SEGA and Epilepsy Management. Management of subependymal giant cell astrocytoma (SEGA) associated with tuberous sclerosis complex (TSC): Clinical recommendations. Eur J Paediatr Neurol 2013; 17: 348-352. 
20. Kaminska B, Ellert-Miklaszewska A, Oberbek A, Wisniewski P, Kaza B, Makowska M, Bretner M, Kazimierczuk Z. Efficacy and mechanism of anti-tumor action of new potential CK2 inhibitors toward glioblastoma cells. Int J Oncol 2009; 35: 1091-1100.

21. Karsy M, Guan J, Cohen AL, Jensen RL, Colman H. New molecular considerations for glioma: IDH, ATRX, BRAF, TERT, H3 K27M. Curr Neurol Neurosci Rep 2017; 17: 19.

22. Koronkiewicz M, Chilmonczyk Z, Kazimierczuk Z. Synergistic anti-leukemic effects of CK2 inhibitors and pentabromobenzylisothioureas in vitro. Anticancer Res 2013; 33: 4891-4899.

23. Kotulska K, Borkowska J, Roszkowski M, Mandera M, Daszkiewicz P, Drabik K, Jurkiewicz E, Larysz-Brysz M, Nowak K, Grajkowska W, Domańska-Pakieła D, Jóźwiak S. Surgical treatment of subependymal giant cell astrocytoma in tuberous sclerosis complex patients. Pediatr Neurol 2014; 50: 307-312.

24. Kotulska K, Jozwiak S. Subependymal giant cell astrocytoma: role of mTOR pathway and its inhibitors. Tumor Cent Nerv Syst 2012; 5: 45-55.

25. Laviv Y, Jackson S, Rappaport ZH. Persistent communicating hydrocephalus in adult tuberous sclerosis patients: a possible therapeutic role for everolimus. Acta Neurochir 2015; 157: 241245.

26. Lawnicka H, Kowalewicz-Kulbat M, Sicinska P, Kazimierczuk Z, Grieb P, Stepien H. Anti-neoplastic effect of protein kinase CK2 inhibitor, 2-dimethylamino-4,5,6,7-tetrabromobenzimidazole (DMAT), on growth and hormonal activity of human adrenocortical carcinoma cell line (H295R) in vitro. Cell Tissue Res 2010; 340: $371-379$

27. Louis DN, Perry A, Reifenberger G, von Deimling A, FigarellaBranger D, Cavenee WK, Ohgaki H, Wiestler OD, Kleihues P, Ellison DW. The 2016 World Health Organization Classification of Tumors of the Central Nervous System: a summary. Acta Neuropathol 2016; 131: 803-820.

28. Mikula M, Hanusek K, Paziewska A, Dzwonek A, Rubel T, Bomsztyk K, Ostrowski J. Halogenated imidazole derivatives block RNA polymerase II elongation along mitogen inducible genes. BMC Mol Biol 2010; 11: 4.

29. Nakada M, Kita D, Watanabe T, Hayashi Y, Teng L, Pyko IV, Hamada J. Aberrant signaling pathways in glioma. Cancers 2011; 3: 3242-3278.

30. Ouyang T, Zhang N, Benjamin T, Wang L, Jiao J, Zhao Y, Zhao Y, Chen J. Subependymal giant cell astrocytoma: current concepts, management, and future directions. Childs Nerv Syst 2014; 30: 561-570.

31. Pagano MA, Andrzejewska M, Ruzzene M, Sarno S, Cesaro L, Bain J, Elliott M, Meggio F, Kazimierczuk Z, Pinna LA. Optimization of protein kinase CK2 inhibitors derived from 4,5,6,7-tetrabromobenzimidazole. J Med Chem 2004; 47: 6239-6247.

32. Pagano MA, Meggio F, Ruzzene M, Andrzejewska M, Kazimierczuk Z, Pinna LA. 2-Dimethylamino-4,5,6,7-tetrabromo-1H-benzimidazole: a novel powerful and selective inhibitor of protein kinase CK2. Biochem Biophys Res Commun 2004; 321: 1040-1044.

33. Ruzzene M, Pinna LA. Addiction to protein kinase CK2: A common denominator of diverse cancer cells? Biochim Biophys Acta 2010; 1804: 499-504.
34. Sarno S, Reddy H, Meggio F, Ruzzene M, Davies SP, DonellaDeana A, Shugar D, Pinna LA. Selectivity of 4,5,6,7-tetrabromobenzotriazole, an ATP site-directed inhibitor of protein kinase CK2 (,casein kinase-2'). FEBS Lett 2001; 496: 44-48.

35. Shehata M, Schnabl S, Demirtas D, Hilgarth M, Hubmann R, Ponath E, Badrnya S, Lehner C, Hoelbl A, Duechler M, Gaiger A, Zielinski C, Schwarzmeier JD, Jaeger U. Reconstitution of PTEN activity by CK2 inhibitors and interference with the PI3-K/Akt cascade counteract the antiapoptotic effect of human stromal cells in chronic lymphocytic leukemia. Blood 2010; 116: 25132521.

36. Tyburczy ME, Kotulska K, Pokarowski P, Mieczkowski J, Kucharska J, Grajkowska W, Roszkowski M, Jozwiak S, Kaminska BW. Novel proteins regulated by mTOR in subependymal giant cell astrocytomas of patients with tuberous sclerosis complex and new therapeutic implications. Am J Pathol 2010; 176: 1878-1890.

37. Weidman DR, Pole JD, Bouffet E, Taylor MD, Bartels U. Doselevel response rates of mTor inhibition in tuberous sclerosis complex (TSC) related subependymal giant cell astrocytoma (SEGA). Pediatr Blood Cancer 2015; 62: 1754-1760.

38. Zien P, Duncan JS, Skierski J, Bretner M, Litchfield DW, Shugar D. Tetra bromobenzotriazole (TBBt) and tetrabromobenzimidazole (TBBz) as selective inhibitors of protein kinase CK2: Evaluation of their effects on cells and different molecular forms of human CK2. Biochim Biophys Acta 2005; 1754: 271-280. 